\title{
CANCER EPIGENETICS AND THE ROLE OF DIETARY ELEMENTS
}

\author{
Farah Abid', Muhammad Saleem 1 , Saleha Yasir' ${ }^{2}$, Shumaila Arshad ${ }^{2}$, Sundus Qureshiं ${ }^{2}$ Mayyda Asif \\ Bajwa $^{3}$, Sana Ashiq ${ }^{4}$, Samreen Tanveer ${ }^{5}$, Mehiwh Qayyum ${ }^{3}$, Kanwal Ashiq ${ }^{3}$ \\ 'Department of Pharmacy, Government College University, Faisalabad, ${ }^{2}$ Faculty of Pharmacy, University of \\ Lahore, Lahore, ${ }^{3}$ Faculty of Pharmaceutical Sciences, The Superior College, Superior University, Lahore, \\ ${ }^{4}$ Centre for Applied Molecular Biology, University of the Punjab, Lahore, ${ }^{5}$ Faculty of Pharmacy, University of the \\ Central Punjab, Lahore, Pakistan
}

\begin{abstract}
Cancer has been a fatal disease since many decades. Over the time, it is presented in multiple ways and is a matter of consideration as accounts for the high rate of mortality. The aim of the current review was to focus on the genetics, epigenetics factors and role of medicinal plants for the cure of this inimical disease. Related articles available in English language (2002-2018) were reviewed with help of different database, including PubMed, Springer Link, Medline, Google Scholar and ScienceDirect. In order to ensure credibility and accuracy of data only those articles were considered which are published in indexed journals i.e. Web of Science and Scopus. This project was conducted at the Department of Pharmacy, Government College University, Faisalabad, Pakistan from 02-01-2019 to 28-02-2019. The genetic machinery is vibrantly involved in the interpretation of the signals and is observed to be affected by various dietary factors. A sequence of modified activities is observed with use of these dietary elements. However, the modification is reviewed through the histone acetyltransferase (HAT), histone deacetylase (HDAC) and DNA methyl transferase (DNMTs), effecting the expression of gene. These modified genes, in turn then express the signals in multiple reformed ways. Different dietary elements that are used such as polyphenol, alkaloid and flavonoids are effective against cancer. The progression of disease involves genetics and epigenetics due to amplification, translocation and mutation during gene expression. Though, many studies have been conducted elaborating the role of plants and their ingredients which play a part in inhibition of cancerous cells by blockade of cell cycle and apoptosis; more in-depth investigations are still required to identify the new drug target and novel therapeutic modalities.
\end{abstract}

KEY WORDS: Cancer; Epigenetics; Histone Acetyltransferase; Histone Deacetylase; Medicinal Plants.

This article may be cited as: Abid F, Saleem M, Yasir Y, Arshad S, Qureshi S, Bajwa MA, et al. Cancer epigenetics and the role of dietary elements [review article]. Gomal J Med Sci 2019 Jul-Sep; 17 (3): 96-104. https://doi. org/10.46903/gjms/17.03.2070

\section{INTRODUCTION}

From the beginning of time, cancer has been presented in a variety of ways. Right from the time of Hippocrates, cancer was named following evidence of thick blood vessels feeding the tumor, acquiring a shape resembling the claw of a crab that grabs the tumor. Later in the era of Laennec, cancer was

\section{Corresponding Author:}

Kanwal Ashiq

Lecturer, Faculty of Pharmaceutical Sciences

The Superior College, Superior University, Lahore, Pakistan

E-mail: kanwal.ashiq@superior.edu.pk

Date Submitted: 17-03-2019

Date Revised: 27-05-2019

Date Accepted: $\quad$ 20-06-2019 considered as a disease that is predisposed at the different stages of cell proliferation. ${ }^{1}$ Last decade has shown up with the development of the genetic model of cancer. Boveri et al. was the first to link cancer with genetics due to the displacement of abnormal chromosome in cancer cells. ${ }^{2}$

Now a great deal of development has been done in the identification of the genes that are marked for the progression of cancer in different organs, like, mutations in ERBB2 and EGFR for the disposition of lung cancer, HER2/NEU mutations in breast cancer, BCR-ABL predisposition in chronic myelocytic leukemia. The studies have revealed the prevalence of disease on the basis of methylation in the DNA, whether it is hyper- or hypomethylation. ${ }^{3}$ Methylation occurs on carbon no. 5 of cytosine. Also, summing up of different functional groups on the histone tails 
is observed. This is a common phenomenon in health and disease to express codes in genomes that vary in population ${ }^{4}$ This involves acetylation and deacetylation of histones. Histones are present as core entrapped in octamers of DNA chains made of 146 base pairs. Among these chains, one is a tetramer $(\mathrm{H} 3-\mathrm{H} 4)$ and two chains are dimers $(\mathrm{H} 2 \mathrm{~A}$ and $\mathrm{H} 2 \mathrm{~B})$. Each core is separated from other by almost 60 basepairs in between. Histone acetylation in chromatin governs activation of genes for expression called as euchromatin while inactivated or closed chromatin doesnot express and is called heterochromatin. The base pairs of DNA are bound to the histone through epsilon-amino acid of lysine. This binding is aided by the enzyme called histone acetyltransferase (HAT). It helps to initiate the modification by acetylation of lysine residue in histones. Another enzyme involved is HDAC, histone de acetylase, meant for deacetylation of the lysine on histones. ${ }^{5}$

As the scenario predicts, epigenetics is concerned with the transfer of the heritable memory in genetics through meiosis and mitosis. The translational mechanistic of DNA is actually involved in the development of the human tissues and organs. The pluripotent cells are destined according to the memory they retain during the translation of DNA. In this process of transfer of heritage through genes: methylation of DNA, chromatin material reassembling and alterations and replacement of histone tails and histones, respectively, is involved. Irregularities in any of these stages may cause cancer lesions. ${ }^{6}$

Now, epigenetics is one of the primary cause in progression of malignancy. Epigenetic disease variations can be influenced by environmental and dietary factors. Animal studies have revealed that environment-induced epigenetic changes can be facilitated by diet. Different dietary elements that are used such as polyphenol and alkaloid are effective against cancer by acting on HDAC. ${ }^{7}$

In DNA methylation, variant other enzymes are involved such as DNMTs which cause DNA silencing and non-coding genomic regions. DNMT1 act as conservative methylating agent while DNMT3a and DNMT3b act to initiate de novo pathway. These are molecular targets in epigenetics for available anti cancer drugs that are approved by FDA. ${ }^{8}$

RNA silencing can occur in two ways: tracriptional and post-transcriptional. Post transcription silencing of genes occurs to produce hetrochromatin thereby wrapping up the chromatin material and the transcription sites. Connection of RNA silencing in different organisms has been studied in detail. For example, in the yeast (Schizoaccharomyces pombe) silencing of different components of the RNA machinery results in the inhibition of methylation of $\mathrm{H} 3 \mathrm{k} 9$ along with disruption of centromere function. ${ }^{9}$

\section{Epigenetics and Dietary components}

\section{Curcumin}

Curcumin obtained from the rhizome of the Curcuma longa, and commonly called as turmeric. It's been used as a traditional drug in Chinese ayurveda medicine. It is under investigation for its beneficial properties. ${ }^{10}$ It contains curcuminoid complex $(80 \%)$, demethoxycurcumin (17\%) and bisdemethoxycurcumin (3\%). In cell culture of tumors, curcumin has shown to have potent inhibitory effects on profliferation of tumors. It also inhibits the tumor development in various xeno-transplant and ortho-transplant mouse models. It has shown anticancer activity with chemopreventive and chemotherapeutic effect with no observable side effects. ${ }^{11}$

\section{HDAC inhibition}

Curcumin is involved in modifying the various protein expressions. It inhibits the cell proliferation, angiogenesis and metastasis of different form of cancer. Curcumin has activity against HDAC. It stimulates apoptotic induced brain cell death through PRAP and caspase 3 by histone deacetylation. ${ }^{12}$

\section{HAT inhibition}

P300/CBP HAT activity is inhibited by curcumin, both, in vivo and in vitro. Curcumin strongly inhibits the $\mathrm{H} 3$ and $\mathrm{H} 4$ acetylation by $\mathrm{p} 300 / \mathrm{CBP}$. These findings are very important in cancer because HAT activity has a significant role in cancer. ${ }^{13}$ Curcumin also reported as epigenetic modulator of TREM-1 gene expression, and this epigenetic modulation in TREM 1 promoter region done by inhibiting p300 activity, which causes hypoacetylation of histone 3 and $4 .{ }^{14} \mathrm{HAT}$, p300 and acetylated CBP/p300 gene expression are down regulated by curcumin. Following reduction in gene expressions used to minimize various diabetic problems by inhibiting high glucose induced proinflammatory cytokines. Curcumin is very effective against the diabetes induced by streptozotacin in male Sprague dawley rats. ${ }^{15}$

\section{Resveratrol}

Red grapes, peanuts and pines are great sources for resveratrol. Dimethyl ether derivative of resveratrol is pterostilbene (3, 5-dimethoxy-4-hydroxystilbene). It is an ayurvedic medicine. These polyphenols have activity against the DNA methyltransferases (DNMTs) enzyme. ${ }^{16}$

\section{HDAC Inhibition}

It was found that when these two compounds are given in combination they inhibit the activity of 
SIRT1, a type III histone deacetylase (HDAC). ${ }^{17}$ Resveratrol causes inhibition of MTA1/NurD complex that is involved in the prostate cancer. This complex over expression in prostate cancer results in tumor aggressiveness. Resveratrol causes suppression of MTA1 protein and causes acetylation of P53. ${ }^{18}$ Resveratrol regulates transcriptional activation and suppression of various genes including p53 and activation of SIRT1. SIRT1 has HDAC activity and thus it is effective against cancer. ${ }^{19}$ Now efforts are being focused to increase bioavailability of resveratrol as it is very effective against cancer. ${ }^{20}$

\section{DNMT Inhibition}

Resveratrol has less DNMT inhibiting activity. However, it prevents epigenetic silencing of BRCA1 which is a tumor suppressor protein. ${ }^{21}$ Another study revealed that resveratrol activating SIRT1 and p300, which are HDAC inhibitors. SIRT1 encoded protein are very important for the treatment of cancer and its chemo preventive action is meditated by resveratrol. ${ }^{22}$

\section{Green tea}

Epigallocatechin (EGCG) found in green tea is a polyphenol that could inhibit DNA methylation. EGCG produces a decrease in an enzyme activity which is called DNMT1. EGCG have anti-neoplastic, anti-inflammatory and antitumor effect. ${ }^{23}$ EGCG may induce apoptosis and cell cycle arrest. EGCG has also been involved in regulation of many signal transduction pathways. The transduction pathway includes JAK/ STAT, MAPK, NF- $\square B$, and AP-1. Additionally, green tea has been involved in induction of tumor suppressor genes p53, p21 and p16. ${ }^{24}$ EGCG induces apoptosis by over expression of TFPI-2. So it is an effective agent for the cure of renal cell carcinoma. ${ }^{25}$ It is also involved in the reduction of expression of hTERT, a major catalytic unit of telomerase..$^{26,27}$

\section{DNMT AND HDAC Inhibition}

Epigenetic regulation by EGCG is important in chemoprevention because of its DNA methyltransferases (DNMTs) and histone acetyltransferases (HATs) inhibition activities. ${ }^{28}$ EGCG activity by inhibition of DNMTs has been shown to lead to global and local hypo methylation of a number of gene promoters. ${ }^{29}$

\section{Genistein}

Genistein (GE) isoflavones, are found in various plants including soya beans. It has anticancer and antiangiogenic activity. Genistein is involved in gene transcription and gene silencing activity by modifying epigenetic events. ${ }^{30}$

Genistein epigenetic modification involves not only in reactivation of tumor suppressor genes but also inhibits the expression of a tumor promoter gene such as hTERT. In human breast cancer cells it involves in transcriptional repression of hTERT expression. It was found that in low concentration, genistein moderately demethylated the GSTP1 tumor suppressor gene promoter and reactivated ts expression in MDA-MB-468 human breast cancer cells. ${ }^{31}$

\section{Apoptosis mechanism}

A study has reported that Genistein (GE) is involved in induction of apoptosis and reduction in proliferation in human prostate cancer. HT-29 and colo320 are suppressed by GE isoflavones. Additionally, other investigation showed that GE inhibits the growth of HCT 116 cells with a dose-dependent manner. Genistein inhibits the augmentation of breast cancer cell lines ADA/MB231, MCF-7 and HBL-100. Peterson and Barnes stated that GE (50 or $100 \mu \mathrm{M})$ inhibits ER-positive breast cancer cell growth in the human. ${ }^{32}$ Numerous investigations have shown that GE causes apoptosis at $50-100 \mu \mathrm{M}$ concentrations. ${ }^{33}$

\section{Cell cycle arrest}

GE causes cell cycle arrest at G2/M in ovarian cancer. In ovarian cancer, GE causes supression of cell cycle arrest at the G2/M phase. Some researchers have reported the relationship between GE and Bcl-2 family. ${ }^{34}$

\section{Inhibition of Metastasis of cancer cells}

Lee et al. investigated that GE can inhibit metastasis of cancer cells. ${ }^{35}$ Another study showed by Zhang et al. and Chen et al. that use of foods rich in soy can decrease the frequency of ovarian cancer. With a high intake of genistein in the women leads to a lowering in the rate of cancer. ${ }^{36}$

\section{Sulforaphane}

Isothiocyanate is found mainly in cruciferous vegetables like cabbage sprouts. It has shown significant activity against the cancer. ${ }^{37}$ Different studies have reported that increase utilization of cruciferous vegetables, expressively decreases cancer risk. ${ }^{38}$ It has shown anticancer effect through various mechanisms, including cell cycle arrest, apoptosis and phase 2 detoxification enzyme. ${ }^{39}$ Sulforaphane (SFN) involved in supression of HDAC activity, and this inhibition involves in epigenetic mechanism. SFN showed an irreversible cell arrest which causes inhibition of cellular growth. In LNCap prostate cancer cells an increase in the G2/M cell cycle arrest was observed after SFN incubation in a concentration and time dependent manner. ${ }^{40}$ SFN induced cell death in different tumor cell lines by increased p53, activated caspase -3 proteins and decrease hypoxia inducible factor -1 alpha activation. ${ }^{41}$ Apoptosis in human breast cancer MDA-MB-231 cells by SFN was initiated by induction of Fas ligand, which triggered the pathway caspase-8, caspase -3and PRAP. ${ }^{37}$ 


\section{Lycophene}

Lycopene is found in tomatoes, and other red fruits. It regulates the expression of various genes pertinent to cell cycle control. It also regulates DNA repair apoptosis in MCF-7 and MDA-MA-231 breast cancer cells. ${ }^{42}$ Lycopene has antioxidant activity. A number of studies showed that it has activity against prostate adenocarcinoma (PCa). ${ }^{43}$ Clinical investigation showed that treatment with lycopene supplementation in men with PCa, decreased DNA damage and serum prostate specific antigen concentrations. ${ }^{44}$ Another study found that Lycopene demethylate is a promoter of the GSTP1 in a breast cancer cell line. ${ }^{31}$

\section{Quercetin}

Quercetin is a natural antioxidant flavonol, present in citrus fruits, onions, parsley, leaves and grains. Quercetin showed anti-cancer activity by regulating mitogenic signaling, cell cycle regulation, apoptotic signaling and metastatic steps in cancer. ${ }^{45}$ It showed a concentration dependent effect on hyper methylation of $p 16^{\prime N K 4 a}$, a tumor suppressor gene, in human colon cancer cell lines (RKO). After 120 $\mathrm{h}$ of treatment with quercetin, it resulted in reversal of hypermethylation. ${ }^{46}$ Quercetin is involved in stimulation of HAT and inactivation or supression of HDAC, both of which are involved in acetylation of H3 histone in leukemia HL60 cells and induces FasL dependent apoptosis. Several studies showed that in vitro anti-cancer activity of quercetin is linked to histone hyperacetylation. Quercetin can inhibit the DNMTs and thus DNA methylation indirectly by changing the concentration of SAM and SAH (S-adenosyl-L-homocysteine) intracellularly. ${ }^{47}$ Quercetin has an effect on histone acetylation. Another study demonstrated that Quercetin decreases the level of COX-2 (cyclooxygenase-2) protein by hindering the binding of various transcription activators such as CREB2, NF- $\square \mathrm{B}, \mathrm{p} 300$, and c-Jun to the promoter of proinflammatory gene COX2, which results in its anti-neoplastic activity. ${ }^{48}$

\section{Garcinol}

Garcinol, a polyisoprenylated benzophenone is derived from Garcinia indica fruit rind. Garcinol strongly inhibits the histone acetyltransferases p300 and PCAF both in vivo and vitro. The kinetic investigation showed that it is a mixed type of inhibition with an augmented affinity for PCAF compared with p300. Garcinol intensely inhibited the HAT activity-dependent chromatin transcription. Additionally, it has been investigated that garcinol is a potent inducer of apoptosis, and it down regulates the global gene expression of HeLa cell lines. ${ }^{49}$

\section{Lunasin}

Lunasin is a 43 amino acid soy peptide. It has been investigated that it showed chemo preventive activity in mammalian cells and in a skin cancer mouse model against oncogenes and chemical carcinogens.
As lunasin involved in inhibition of core histone acetylation, this activity of lunasin led to proposal of epigenetic mechanism. Soy lunasin and synthetic lunasin both are involved in inhibition of core histone acetylation in a dose-dependent manner. ${ }^{50}$

\section{Parthenolide}

Parthenolide (PN) is a sesquiterpene lactone obtained from Tanacetumparthenium. It has been investigated that parthenolide involved in induction of apoptosis and cell cycle arrest. ${ }^{51} \mathrm{PN}$ was shown to precisely deplete HDAC1. HDAC1 depletion was occurred through proteasomal degradation. PN led to depletion of HDAC1 which causes the ubiquitination of MDM2 result in activation of P53 and sustained DNA damage response. ${ }^{52}$

\section{Anacardic acid}

Anacardic acid 6 pentadecyl salicylic acid is an effective inhibitor of HAT. It inhibits p300 and p300/ CBP-linked HAT activities. ${ }^{53}$

\section{Garlic, Onions}

They are members of the allium family that consist of a complex range of water-soluble and fat-soluble organ sulfur compounds. These organosulphur have activity against cancer and employed in cancer treatment. ${ }^{54}$

Garlic constitutes allyl derivatives which are amongst the first compounds having an impact on histone acetylation. Allyl mercaptan (AM), diallyl disulfide (DADS), S-allylcysteine (SAC), S-allylmercaptocysteine (SAMC) and allicin showed increased acetylation of histone $(\mathrm{H} 3 / \mathrm{H} 4)$ in human cancer cells. ${ }^{55}$ AM responsible for causing $\mathrm{H} 3$ hyperacetylation and facilitated Sp3 and p53 binding on the P21WAF1 promoter in human colon cancer cells. ${ }^{56}$ Preclinical studies in vitro and in vivo showed the importance of garlic-derived organosulfur compounds in prostate cancer prevention. ${ }^{57}$ DAD caused increase in histone acetylation and apoptosis in cancer like prostate cancer. ${ }^{54} \mathrm{AM}$ on human colon cancer cells causes rapid histone acetylation along with HDAC inhibition. ${ }^{56}$

\section{Selenium}

Selenium is an important trace element found generally in inorganic forms. While in its organic forms, it is found in Brazil within nuts and seafood. Selenium have an anticarcinogenic effect coming from its selenoprotein and importantly organoselenium metabolites. ${ }^{58}$ It is a broad spectrum anticancer agent, found in lungs, ovarian, liver bladder and colon. Many of its forms are involved in epigenetic effect via histone modification.It decreases the HDAC activity and increases histone acetylation while many of its forms are involved in epigenetic changes. Some of the forms include sodium selenite, keto-methylselenobutyrate (KMSB), methyl selenocysteine (MSC), and methyl selenopyruvate (MSP). ${ }^{59,54}$ 


\section{Silymarin (silibinin)}

The flavonolignansilibinin is an active component of the milk thistle plant (Silybummarianum) that has been reported to increase acetylation of histones in hepatic cancer. Silibinin has exhibited increased acetylation of histone $\mathrm{H} 3$ and $\mathrm{H} 4$ in vitro in $\mathrm{HuH} 7$ cells ${ }^{60}$ and in vivo in $\mathrm{HuH} 7$ xenografts in nude mice. ${ }^{61}$ It also causes inhibition of HDAC activity and decreased HDAC levels and found to reduce DNMT activity in SW480 and SW620 cell lines following $72 \mathrm{~h}$ of treatment. ${ }^{62}$

\section{Rosmarinic Acid}

Rosmarinic Acid is an ester of caffeic acid and naturally occurring phenolic compound. It has been reported that rosmarinic acid has a number of potential biological activities like anti-viral, antibacterial, anti-inflammatory and anticancer activities. ${ }^{63}$ Rosmarinic acid has an inhibitory effect on DNA methyltrasnferase. In human breast cancer cell line MCF7 has shown decreased activity of methytransferase. ${ }^{64} \mathrm{In}$ cancer, DNA methylation undergoes aberrant changes resulting in variety of tumor suppressor genes undergoing promoter hypermethylation and becoming transcriptionally silent leading to tumor formation. Inhibition of DNA methyltransferase reverses the effect with rosmarinic acid having potential therapeutic effect against cancer. It has been investigated that rosmarinic acid may inhibit the bone metastasis from breast carcinoma by the NF kappaB ligand RANKL)/ RANK/osteoprotegerin (OPG with suppression of expression of interleukin 8. OPG factor is proangiogenic and through its inhibition, inhibition of metastasis of cancer cells can be achieved. ${ }^{65}$

\section{Plumbagin}

Plumbagin is a natural compound isolated from plants of the family Plumbaginaceae as well as from plants belonging to the family of Droseraceae. In India and China, plants extracts from these families have been traditionally employed in the treatment of an array of microbial and allergic diseases. The anti-cancer, anti-hyperlipidemic and anti-artherosclerotic actions of 5-hydroxy-2-methyl-1, 4-naphthaquinone (Plumbagin) is revealed by many research studies in the past. PL mediates an anti-tumorigenesis effect through the utilization of various molecular mechanisms including NF- $\square \mathrm{b}$ and Bcl-2 inactivation, network of microtubule disruption and DNA breakage. In addition to these mechanisms, arresting of the cell cycle and reactive oxygen specie generation is also invovled. ${ }^{66}$ The $\mathrm{H} 460$ lung cancer cell lines are more sensitive to plumbagin than A549 cells. The mechanism of action through which plumbagin targets $\mathrm{H} 460$ cells is the modulation of EGFR mediated AKt signaling pathway. Furthermore, the compound induces apoptosis through the arrest of $G_{2} / M$. The cell viability is also inhibited through the actions of PL. ${ }^{67}$ In human breast cancer MCF-7 cell lines, PL induces potent cytotoxicity in a manner which is ROS dependent because a crucial role is played by ROS in the induction of cell dealth. ${ }^{68}$ Plumbagin mediates its anti-cancer potential in a dose and time dependent manner. Human GC cells are also susceptible to the anti-cancer capacities of plumbagin. The human GC cells in response to therapy with the biologically active principle demonstrated growth inhibition, apotosis and an increase in chemosensitivity. ${ }^{69}$

\section{Pomiferin}

The osage orange fruit is the source of prenylated isoflavone known as Pomiferin which demonstrates, a remarkably potent free radical scavenging capacity. The photochemi-luminescence assay system of pomiferin exhibits a strong anti-oxidant activity against the superoxide anion. A selective anti-tumor growth against human breast cancer MCF-7 cell lines is observed in vitro with pomiferin ${ }^{70}$ also showing a cytokeratin downregulation, in a proteomics approach. In Vitro studies involving Human-Dermal-Fibroblasts, it reveals its potent protein stimulant capabilities in the extracellular matrix. ${ }^{71}$

\section{Sanguinarine}

Sanguinarine demonstrates potent anti-proliferative activity against various types of cancer i.e. oral squamous cell carcinoma. It is an alkaloid belonging to the class of benzophenanthridine, demonstrating a selective action against prostate cancer cells through inhibition of survivin with negligible effects on normal prostate cells. The expression of survivin protein is inhibited through the degradation of proteins through the utilization of ubiquitin-proteasome system. ${ }^{72}$ In addition to anti-invasive and anti-tumorigenisis effects, sanginarine also mediates anchorage independent cell growth inhibition. ${ }^{73}$ The progression of prostrate cancer, which is castration resistant, is promoted by altered expression of survivin. The bioactive principle is also known to cause blockade of the cell cycle as well as apoptosis in human prostate cancer cells through the modulation of machinery of cell cycle and apoptosis. ${ }^{72}$

\section{CONCLUSION}

Cancer date backs to the era of Hippocrates, always known fatal to human life. It has shown up in multiple ways affecting almost all organs of the body. Its association to the genes has been thoroughly studied and evaluated for any possible counter. Genetics have contributed to cancer mortalities via signals and shown direct linked to diet related factors. Modified activities of genes are observed in association to these factors including histone acetyltransferase (HAT), histone deacetylase (HDAC), DNA methyl transferase (DNMTs) etc. effecting the expression in totality. Numerous studies have been conducted elaborating the role of plants and their ingredients play a part in inhibition of cancerous 
cells by blockade of cell cycle and apoptosis or as the case may be.

\section{REFERENCES}

1. Pitot HC. Fundamentals of Oncology, Revised and expanded. 4th ed. Florida: CRC Press; 2002. https://doi.org/10.3109/9780203910320

2. Boveri T. The Origin of Malignant Tumors. Williams and Wilkins: Baltimore, MD;1929.

3. Feinberg AP, Ohlsson R, Henikoff S. The epigenetic progenitor origin of human cancer. Nat Rev Genet 2006 Jan;7(1):21-33. https://doi. org/10.1038/nrg1748

4. Szulwach KE, Jin P. Integrating DNA methylation dynamics into a framework for understanding epigenetic codes. Bioessays 2014 Jan;36(1):107-17. https://doi.org/10.1002/bies.201300090

5. Davis CD, Ross SA. Dietary components impact histone modifications and cancer risk. Nutr Rev 2007 Feb 1;65(2):88-94. https://doi. org/10.1111/j.1753-4887.2007.tb00285.x

6. Ducasse M, Brown MA. Epigenetic aberrations and cancer. Mol Cancer 2006 Dec 1;5(1):60. https://doi.org/10.1186/1476-4598-5-60

7. Nian H, Bisson WH, Dashwood WM, Pinto JT, Dashwood RH. Q-Keto acid metabolites of organoselenium compounds inhibit histone deacetylase activity in human colon cancer cells. Carcinogenesis 2009 Aug 1;30(8):1416-23. https:// doi.org/10.1093/carcin/bgp147

8. Bird A. DNA methylation patterns and epigenetic memory. Genes Dev 2002 Jan 1;16(1):6-21. https://doi.org/10.1101/gad.947102

9. Volpe T, Schramke V, Hamilton GL, White SA, Teng G, Martienssen RA, et al. RNA interference is required for normal centromere function infission yeast. Chromosome Res 2003 Feb 1;11(2):13746. https://doi.org/10.1023/A:1022815931524

10. Aggarwal BB, Sung B. Pharmacological basis for the role of curcumin in chronic diseases: an age-old spice with modern targets. Trends Pharmacol Sci 2009 Feb 1;30(2):85-94. https://doi. org/10.1016/j.tips.2008.11.002

11. Anand $P$, Thomas SG, Kunnumakkara AB, Sundaram C, Harikumar KB, Sung B, et al. Biological activities of curcumin and its analogues (Congeners) made by man and Mother Nature. Biochem Pharmacol 2008 Dec 1;76(11):1590-611. https:// doi.org/10.1016/j.bcp.2008.08.008

12. Marcu L, Olver I. Tirapazamine: from bench to clinical trials. Curr Clin Pharmacol 2006 Jan 1;1 (1):719. https://doi.org/10.2174/157488406775268192

13. Morimoto T, Sunagawa $\mathrm{Y}$, Kawamura T, Takaya T, Wada H, Nagasawa A, et al. The dietary compound curcumin inhibits p300 histone acetyltransferase activity and prevents heart failure in rats. J Clin Invest 2008 Mar 3;118(3):868-78. https://doi.org/10.1172/JCl33160

14. Xie P, Zhang W, Yuan S, Chen Z, Yang Q, Yuan
D. Suppression of experimental choroidal neovascularization by curcumin in mice. PloS one 2012; 7(12):e53329. doi: 10.1371/journal. pone.0053329. https://doi.org/10.1371/journal. pone.0053329

15. Chiu J, Khan ZA, Farhangkhoee H, Chakrabarti $\mathrm{S}$. Curcumin prevents diabetes-associated abnormalities in the kidneys by inhibiting p300 and nuclear factor-[B. Nutr 2009 Sep 1;25(9):964-72. https://doi.org/10.1016/j.nut.2008.12.007

16. Gracia A, Elcoroaristizabal X, Fernández-Quintela A, Miranda J, Bediaga NG, de Pancorbo MM, et al. Fatty acid synthase methylation levels in adipose tissue: effects of an obesogenic diet and phenol compounds. Genes Nutr 2014 Jul 1;9(4):411. https://doi.org/10.1007/s12263-014-0411-9

17. Rajendran P, Ho E, Williams DE, Dashwood RH. Dietary phytochemicals, HDAC inhibition, and DNA damage/repair defects in cancer cells. Clin Epigenetics 2011 Dec;3(1):4. https://doi. org/10.1186/1868-7083-3-4

18. Kai L, Samuel SK, Levenson AS. Resveratrol enhances p53 acetylation and apoptosis in prostate cancer by inhibiting MTA1/NuRD complex. Int $\mathrm{J}$ Cancer 2010 Apr 1;126(7):1538-48. https://doi. org/10.1002/ijc.24928

19. Binda O, Nassif C, Branton PE. SIRT1 negatively regulates HDAC1-dependent transcriptional repression by the RBP1 family of proteins. Oncogene 2008 May;27(24):3384-92. https://doi. org/10.1038/sj.onc.1211014

20. Ndiaye M, Kumar R, Ahmad N. Resveratrol in cancer management: where are we and where we go from here? Ann N Y Acad Sci 2011 Jan;1215(1):144-9. https://doi.org/10.1111/ j.1749-6632.2010.05851.x

21. Papoutsis AJ, Lamore SD, Wondrak GT, Selmin OI, Romagnolo DF. Resveratrol prevents epigenetic silencing of BRCA-1 by the aromatic hydrocarbon receptor in human breast cancer cells. J Nutr 2010 Sep 1;140(9):1607-14. https://doi.org/10.3945/ jn.110.123422

22. Howitz KT, Bitterman KJ, Cohen HY, Lamming DW, Lavu S, Wood JG, et al. Small molecule activators of sirtuins extend Saccharomyces cerevisiae lifespan. Nature 2003 Sep;425(6954):191-6. https:// doi.org/10.1038/nature01960

23. Roy AM, Baliga MS, Katiyar SK. Epigallocatechin-3-gallate induces apoptosis in estrogen receptor-negative human breast carcinoma cells via modulation in protein expression of p53 and Bax and caspase- 3 activation. Mol Cancer Ther 2005 Jan 1;4(1):81-90.

24. Li Y, Li X, Guo B. Chemopreventive agent 3, 3ロ-diindolylmethane selectively induces proteasomal degradation of class I histone deacetylases. Cancer Res 2010 Jan 15;70(2):646-54. https://doi. org/10.1158/0008-5472.CAN-09-1924

25. Gu B, Ding Q, Xia G, Fang Z. EGCG inhibits growth and induces apoptosis in renal cell carcinoma 
through TFPI-2 overexpression. Oncol Rep 2009 Mar 1;21(3):635-40. https://doi.org/10.3892/ or_00000266

26. Lee YH, Kwak J, Choi HK, Choi KC, Kim S, Lee J, et al. EGCG suppresses prostate cancer cell growth modulating acetylation of androgen receptor by anti-histone acetyltransferase activity. Int $\mathrm{J}$ Mol Med 2012 Jul 1;30(1):69-74.

27. Chen H, Li Y, Tollefsbol TO. Strategies targeting telomerase inhibition. Mol Biotechnol $2009 \mathrm{Feb}$ 1;41(2):194-9. https://doi.org/10.1007/s12033008-9117-9

28. Choi KC, Jung MG, Lee YH, Yoon JC, Kwon SH, Kang HB, et al. Epigallocatechin-3-gallate, a histone acetyltransferase inhibitor, inhibits EBV-induced B lymphocyte transformation via suppression of RelA acetylation. Cancer Res 2009 Jan 15;69(2):583-92. https://doi.org/10.1158/00085472.CAN-08-2442

29. Meeran SM, Ahmed A, Tollefsbol TO. Epigenetic targets of bioactive dietary components for cancer prevention and therapy. Clin Epigenetics 2010 Dec;1(3):101. https://doi.org/10.1007/s13148010-0011-5

30. Li Y, Yuan YY, Meeran SM, Tollefsbol TO. Synergistic epigenetic reactivation of estrogen receptor- $\square$ (ER $\square$ ) by combined green tea polyphenol and histone deacetylase inhibitor in ER $\square$-negative breast cancer cells. Mol cancer 2010 Dec 1;9(1):274. https://doi.org/10.1186/1476-4598-9-274

31. King-Batoon A, Leszczynska JM, Klein CB. Modulation of gene methylation by genistein or lycopene in breast cancer cells. Environ Mol Mutagen 2008 Jan;49(1):36-45. https://doi.org/10.1002/ em.20363

32. Chen Y, Huang C, Zhou T, Chen G. Genistein induction of human sulfotransferases in HepG2 and Caco-2 cells. Basic Clin Pharmacol Toxicol 2008 Dec;103(6):553-9. https://doi.org/10.1111/j.17427843.2008.00316.x

33. Chang KL, Cheng HL, Huang LW, Hsieh BS, Hu YC, Chih TT, et al. Combined effects of terazosin and genistein on a metastatic, hormone-independent human prostate cancer cell line. Cancer Lett 2009 Apr 8;276(1):14-20. https://doi. org/10.1016/j.canlet.2008.10.033

34. Banerjee S, Li Y, Wang Z, Sarkar FH. Multi-targeted therapy of cancer by genistein. Cancer Lett 2008 Oct 8;269(2):226-42. https://doi. org/10.1016/j.canlet.2008.03.052

35. Lee JY, Kim HS, Song YS. Genistein as a potential anticancer agent against ovarian cancer. J Tradit Complement Med 2012 Apr 1;2(2):96-104. https:// doi.org/10.1016/S2225-4110(16)30082-7

36. Zhang M, Xie X, Lee AH, Binns CW. Soy and isoflavone intake are associated with reduced risk of ovarian cancer in southeast china. Nutr Cancer 2004 Jul 1;49(2):125-30. https://doi.org/10.1207/ s15327914nc4902_2
37. Pledgie-Tracy A, Sobolewski MD, Davidson $\mathrm{NE}$. Sulforaphane induces cell type-specific apoptosis in human breast cancer cell lines. Mol Cancer Ther 2007 Mar 1;6(3):1013-21. https://doi. org/10.1158/1535-7163.MCT-06-0494

38. McCullough ML, Robertson AS, Chao A, Jacobs EJ, Stampfer MJ, Jacobs DR, et al. A prospective study of whole grains, fruits, vegetables and colon cancer risk. Cancer Cause Control 2003 Dec 1;14(10):959-70. https://doi.org/10.1023/B:CACO.0000007983.16045.a1

39. Sivils JC, Ancrum TM, Bain LJ. LOSS of Mrp1 alters detoxification enzyme expression in a tissue-and hormonal-status-specific manner. J Appl Toxicol 2013 Aug;33(8):766-73. https://doi. org/10.1002/jat.2727

40. Singh SV, Herman-Antosiewicz A, Singh AV, Lew KL, Srivastava SK, Kamath R, et al. Sulforaphane-induced G2/M phase cell cycle arrest involves checkpoint kinase 2-mediated phosphorylation of cell division cycle $25 \mathrm{C}$. J Biol Chem 2004 Jun 11;279(24):25813-22. https://doi. org/10.1074/jbc.M313538200

41. Jeong JK, Moon MH, Seo JS, Seol JW, Lee YJ, Park SY. Sulforaphane blocks hypoxia-mediated resistance to TRAIL-induced tumor cell death. Mol Med Rep 2011 Mar 1;4(2):325-30. https:// doi.org/10.3892/mmr.2011.422

42. Chalabi N, Delort L, Le Corre L, Satih S, Bignon YJ, Bernard-Gallon D. Gene signature of breast cancer cell lines treated with lycopene. Pharmacogenomics 2006 Aug 3;7(5):1-10. https://doi. org/10.2217/14622416.7.5.663

43. Lu QY, Hung JC, Heber D, Go VL, Reuter VE, Cordon-Cardo C, et al. Inverse associations between plasma lycopene and other carotenoids and prostate cancer. Cancer Epidemiol Biomarkers 2001 Jul 1;10(7):749-56.

44. Kucuk O, Sarkar FH, Djuric Z, Sakr W, Pollak MN, Khachik F, et al. Effects of lycopene supplementation in patients with localized prostate cancer. Exp Biol Med 2002 Nov;227(10):881-5. https:// doi.org/10.1177/153537020222701007

45. Arshad S, ur Rehman M, Abid F, Yasir S, Qayyum $\mathrm{M}$, Ashiq K, et al. Current situation of breast cancer in Pakistan with the available interventions. Int J Biosci 2019;11(6):232-40.

46. Tan S, Wang C, Lu C, Zhao B, Cui Y, Shi X, et al. Quercetin is able to demethylate the p16INK4a gene promoter. Chemotherapy 2009;55(1):6-10. https://doi.org/10.1159/000166383

47. Lee WJ, Chen YR, Tseng TH. Quercetin induces FasL-related apoptosis, in part, through promotion of histone $\mathrm{H} 3$ acetylation in human leukemia HL-60 cells. Oncol Rep 2011 Feb 1;25(2):583-91. https://doi.org/10.3892/or.2010.1097

48. Xiao X, Shi D, Liu L, Wang J, Xie X, Kang T, et al. Quercetin suppresses cyclooxygenase-2 expression and angiogenesis through inactivation of P300 signaling. PloS One 2011;6(8):e22934. 
doi: 10.1371/journal.pone.0022934. https://doi. org/10.1371/journal.pone.0022934

49. Balasubramanyam K, Altaf M, Varier RA, Swaminathan V, Ravindran A, Sadhale PP, et al. Polyisoprenylatedbenzophenone, garcinol, a natural histone acetyltransferase inhibitor, represses chromatin transcription and alters global gene expression. J Biol Chem 2004 Aug 6;279(32):3371626. https://doi.org/10.1074/jbc.M402839200

50. Jeong HJ, Jeong JB, Kim DS, de Lumen BO. Inhibition of core histone acetylation by the cancer preventive peptide lunasin. J Agric Food Chem 2007 Feb 7;55(3):632-7. https://doi.org/10.1021/ jf062405u

51. Pajak B, Gajkowska B, Orzechowski A. Molecular basis of parthenolide-dependent proapoptotic activity in cancer cells. Folia Histochem Cytobiol 2008;46(2):129-35. https://doi.org/10.2478/ v10042-008-0019-2

52. Qayyum M, Ashiq K, Tanveer S, Bajwa MA, ShahRukh A, Jahangir N, et al. Review on phytochemical evaluation and extraction of Nigella sativa (Kalongi) with pharmacological and traditional applications. Int J Biosci 2020 Mar 18;16(3): 231-41.

53. Balasubramanyam K, Swaminathan V, Ranganathan A, Kundu TK. Small molecule modulators of histone acetyltransferase p300. J Biol Chem 2003 May 23;278(21):19134-40. https://doi. org/10.1074/jbc.M301580200

54. Nian H, Delage B, Ho E, Dashwood RH. Modulation of histone deacetylase activity by dietary isothiocyanates and allyl sulfides: studies with sulforaphane and garlic organosulfur compounds. Environ Mol Mutagen 2009 Apr;50(3):213-21. https://doi.org/10.1002/em.20454

55. Lea MA, Rasheed M, Randolph VM, Khan F, Shareef A, DesBordes C. Induction of histone acetylation and inhibition of growth of mouse erythroleukemia cells by S-allylmercaptocysteine. Nutr Cancer 2002 May 1;43(1):90-102. https://doi. org/10.1207/S15327914NC431_11

56. Nian H, Delage B, Pinto JT, Dashwood RH. Allylmercaptan, a garlic-derived organosulfur compound, inhibits histone deacetylase and enhances Sp3 binding on the P21WAF1 promoter. Carcinogenesis 2008 Sep 1;29(9):1816-24. https://doi.org/10.1093/carcin/bgn165

57. Xiao D, Zeng Y, Singh SV. Diallyltrisulfide-induced apoptosis in human cancer cells is linked to checkpoint kinase 1-mediated mitotic arrest. Mol Carcinog 2009 Nov;48(11):1018-29. https://doi. org/10.1002/mc.20553

58. Hatfield DL, Yoo MH, Carlson BA, Gladyshev VN. Selenoproteins that function in cancer prevention and promotion. Biochim Biophys Acta 2009 Nov 1;1790(11):1541-5. https://doi.org/10.1016/j. bbagen.2009.03.001

59. Lee JI, Nian H, Cooper AJ, Sinha R, Dai J, Bisson WH, et al. $\square$-Keto acid metabolites of naturally occurring organoselenium compounds as inhibitors of histone deacetylase in human prostate cancer cells. Cancer Prev Res 2009 Jul 1;2(7):683-93. https://doi.org/10.1158/1940-6207. CAPR-09-0047

60. Lah JJ, Cui W, Hu KQ. Effects and mechanisms of silibinin on human hepatoma cell lines. World J Gastroenterol 2007 Oct 28;13(40):5299. https:// doi.org/10.3748/wjg.v13.i40.5299

61. Cui W, Gu F, Hu KQ. Effects and mechanisms of silibinin on human hepatocellular carcinoma xenografts in nude mice. World J Gastroenterol 2009 Apr 28;15(16):1943. https://doi.org/10.3748/ wjg. 15.1943

62. Mateen S, Raina K, Jain AK, Agarwal C, Chan $D$, Agarwal R. Epigenetic modifications and p21-cyclin B1 nexus in anticancer effect of histone deacetylase inhibitors in combination with silibinin on non-small cell lung cancer cells. Epigenetics 2012 Oct 13;7(10):1161-72. https:// doi.org/10.4161/epi.22070

63. Petersen M, Simmonds MS. Rosmarinic acid. Phytochemistry 2003 Jan 1;62(2):121-5. https:// doi.org/10.1016/S0031-9422(02)00513-7

64. Paluszczak J, Krajka-Ku $\square$ niak V, Baer-Dubows$k a \mathrm{~W}$. The effect of dietary polyphenols on the epigenetic regulation of gene expression in MCF7 breast cancer cells. Toxicol Lett 2010 Feb 1;192(2):119-25. https://doi.org/10.1016/j. toxlet.2009.10.010

65. Xu Y, Jiang Z, Ji G, Liu J. Inhibition of bone metastasis from breast carcinoma by rosmarinic acid. Planta Med 2010 Jul;76(10):956-62. https://doi. org/10.1055/s-0029-1240893

66. Tian L, Yin D, Ren YE, Gong C, Chen A, Guo FJ. Plumbagin induces apoptosis via the p53 pathway and generation of reactive oxygen species in human osteosarcoma cells. Mol Med Rep 2012 Jan 1;5(1):126-32.

67. Gomathinayagam R, Sowmyalakshmi S, Mardhatillah F, Kumar RA, Akbarsha MA, Damodaran C. Anticancer mechanism of plumbagin, a natural compound, on non-small cell lung cancer cells. Anticancer Res 2008 Mar 1; 28(2A):785-92.

68. Lee JH, Yeon JH, Kim H, Roh W, Chae J, Park $\mathrm{HO}$, et al. The natural anticancer agent plumbagin induces potent cytotoxicity in MCF-7 human breast cancer cells by inhibiting a Pl-5 kinase for ROS generation. PloS One 2012; 7(9):e45023. doi: 10.1371/journal.pone.0045023. https://doi. org/10.1371/journal.pone.0045023

69. Li J, Shen L, Lu FR, Qin Y, Chen R, Li J, et al. Plumbagin inhibits cell growth and potentiates apoptosis in human gastric cancer cells in vitro through the NF- $\mathrm{BB}$ signaling pathway. Acta Pharmacol Sin 2012 Feb;33(2):242-9. https://doi. org/10.1038/aps.2011.152

70. Yang R, Hanwell H, Zhang J, Tsao R, Meckling $\mathrm{KA}$. Antiproliferative activity of pomiferin in normal (MCF-10A) and transformed (MCF-7) breast epithelial cells. J Agric Food Chem 2011 
Dec 28;59(24):13328-36. https://doi.org/10.1021/ jf202898g

71. Gruber JV, Holtz R, Sikkink SK, Tobin DJ. In vitro and ex vivo examination of topical Pomiferin treatments. Fitoterapia 2014 Apr 1;94:164-71. https:// doi.org/10.1016/j.fitote.2014.01.023

72. Sun M, Lou W, Chun JY, Cho DS, Nadiminty N, Evans CP, et al. Sanguinarine suppresses prostate tumor growth and inhibits survivin expression. Genes Cancer 2010 Mar;1 (3):283-92. https://doi. org/10.1177/1947601910368849

73. Tsukamoto $\mathrm{H}$, Kondo S, Mukudai $\mathrm{Y}$, Nagumo T, Yasuda A, Kurihara Y, et al. Evaluation of anticancer activities of benzo [c] phenanthridine alkaloid sanguinarine in oral squamous cell carcinoma cell line. Anticancer Res 2011 Sep 1;31(9):2841-6.

CONFLICT OF INTEREST
Authors declare no conflict of interest.
GRANT SUPPORT AND FINANCIAL DISCLOSURE
None declared.

\section{AUTHORS' CONTRIBUTION}

The following authors have made substantial contributions to the manuscript as under:

Conception or Design:

FA, MS

Acquisition, Analysis or Interpretation of Data:

FA, MS, SY, SQ, KA, SA, SA

Manuscript Writing \& Approval:

$F A, M S, M A B, S T, M Q, K A, S A, S A$

All the authors agree to be accountable for all aspects of the work in ensuring that questions related to the accuracy or integrity of any part of the work are appropriately investigated and resolved. 